\title{
Clarity about the base quantity "amount of substance" is required before (re)definition of the associated base unit mole is meaningful
}

\author{
Paul De Bièvre ${ }^{1}$
}

Published online: 30 July 2015

(c) Springer-Verlag Berlin Heidelberg 2015

The general concept 'quantity' refers to abstract constructs which we have conceived in our mind to enable us to describe our perception of the chemical and physical world. From the large number of possible quantities, constituting the ISQ (International System of Quantities-Système International de Grandeurs-), entry 1.6 in [1], seven specific ones have been selected as 'base quantities' by convention [2], assumed independent from each other: length, mass, time, electric current, temperature, amount of substance, and luminous intensity. The responsibility for the ISQ lies with the International Organization for Standardization, ISO, Technical Committee TC 12, Quantities and Units [3].

Comparing the size of kind-of-quantities, entry 1.2 in [1], can lead us to the conclusion "larger" or "smaller" (e.g., larger mass or smaller mass). Changing these qualitative expressions larger or smaller into specific values (e.g., $1.15 \mathrm{~kg}$ vs. $0.98 \mathrm{~kg}$ ) by measurements, enables us to arrive at quantitative statements that contain much more information. This is achieved by the use of measurement units (in this example: the $\mathrm{kg}$ ). A unit is one specific value for the quantity concerned (in this case: mass) defined by convention, i.e., by an agreement. By performing a measurement, we can then express the size of a given quantity

Disclaimer The author is a member of the Joint Committee on Guides for Metrology (JCGM), Working Group 2 (VIM). The opinions expressed in this column do not necessarily represent the view of the working group or of ACQUAL.

Paul De Bièvre

paul.de.bievre@skynet.be

$1 \quad$ Kasterlee, Belgium
$Q$ (e.g., the mass of a thing) as a number $\{Q\}$ (e.g., 1.15) of measurement units times a mass defined as a common measurement unit $[Q]$ (in this example: $\mathrm{kg}$ ). The summarizing equation is: $Q=\{Q\}[Q]$. See description in entry 1.25 in [1]. This is true for any quantity. The seven selected base units assigned to the seven base quantities constitute our International System of Units (SI); see entry 1.16 in [1] ("SI" comes from the French: Système International d'Unités).

For the quantity 'amount of substance' the unit is the mole (symbol mol). It was added as seventh base quantity to the list of six in 1971. Redefinition of the seven base units, in particular of the mole, has now been widely discussed during about 10 years in the educational literature for chemistry, especially for analytical chemistry. The numerous questions as well as the sense of confusion in this community continue to be outspoken and permanent: the reader is advised to consult the literature references given as a service to the readers of ACQUAL in previous columns in this journal [4-6]. One of the explanations of this confusion may be amazingly simple: The "chemists' view" in 1971 on the matter was formulated by physical chemists, assembled in Divison I "Physical Chemistry" of the IUPAC (International Union of Pure and Applied Chemistry). This happened again in 2009 when an IUPAC view was developed: born from a Division I-inspired formulation at the request of the CCU (Comité Consultatif des Unités-Consultative Committee for Units) and then channeled through IUPAC's ICTNS (Interdivisional Committee on Terminology, Nomenclature and Symbols), then to the IUPAC Executive, which turned it into an "IUPAC view." It did not reflect the different concept analytical chemists had-and still have-about the Avogadro number (unitless): rather than being a (fundamental, 
later called reference) constant, giving rise to a base quantity 'amount of substance' (with a unit mol). IUPAC's request at that date (2009) to CCQM (Comité Consultatif pour la Quantité de Matière-Consultative Committee for Amount of Substance) [7] to coin a new name for the base quantity concerned, is still not answered to this very day as described in [4]. Since that has not (yet?) happened, attention is again drawn in this column on this very important request. It is also noteworthy that a Consultative Committee such as CCQM to CIPM (Comité International des Poids et Mesures-International Committee of Weights and Measures) has not yet explained the description of its task, described in its name. This column brings this observation back to the attention of the chemical community, although that has been done previously in an attempt to restart the discussion within IUPAC. Fortunately, that now seems to be underway.

To define a base unit acceptable to all, the base quantity to which that unit is allocated, must be well-and commonly-understood. For instance, if we want to define the unit kilogram, we first have to understand the concept 'mass'; if we want to define the unit meter, we first have to understand the concept 'length'; and if we want to define the unit ampere, we first have to understand the concept 'electric current'. When the concept 'amount of substance' was included in the SI in 1971 [8], the inverse reasoning entered the international scene: a unit mole understood as a number of entities (atoms/molecules/electrons/ions, etc.) by analytical chemists was seen as being in search of an associated quantity. The educators in chemistry who had to explain the official concept 'amount of substance' in simple, clear language, never achieved to teach a commonly understood and implemented version. The 'official' version was perceived as 'strange' and not compatible with the practice in the analytical laboratory. The logical consequence of attempting to teach the concept was widespread confusion about 'amount of substance' (hence also about the unit itself) for ensuing generations. A good check of this is the question which any reader is invited to answer and to explain for himself: "what is 'amount of substance'?"

The variety of opinions about 'amount of substance' is illustrated in a number of publications, quoted, e.g., in [9]. The use of "number of moles" was continued-although discouraged by IUPAC [10]-and was described sometimes in the form of a self-fulfilling prophecy: "the quantity of which the mole is the unit" [9] or, as in a wellknown chemistry textbook:

“... practicing chemists prefer to talk about “... number of moles". Take the advice of your instructor on whether or not to use the official term" [11].

It follows from the above that the present discussions on the redefinition of the unit mole automatically lead to the question: what is our common understanding of the concept 'amount of substance'? Numerous publications are quoted in [12] describing the disarray of teachers in chemistry who do not find a clear answer to this question.

In an attempt to better understand, we go back to 1971: What happened after the introduction of the concept 'amount of substance' (and its unit 'mole') in that year? The physical chemists were satisfied because at that time they thought in packages (or "collections" or "ensembles" or "aggregates") of a very large (but unknown) number of entities relative to another set of large (but also unknown) number of entities in $12 \mathrm{~g}$ of ${ }^{12} \mathrm{C}$, used in the thermodynamical calculations of physical chemistry. No numbers of atoms/molecules were needed, just a "large package" of entities defined as follows [8]:

1. The mole is the amount of substance of a system which contains as many elementary entities as there are atoms in $0.012 \mathrm{~kg}$ of carbon 12; its symbol is "mol".

2. When the mole is used, the elementary entities must be specified and may be atoms, molecules, ions, electrons, other particles, or specified groups of such particles.

Conclusion No need to know the actual number of entities in a thus defined mole. And there is nothing wrong with that. But thinking in terms of numbers of single entities (not "packages of entities of atoms and molecules") is a very different way of thinking about the chemical world [12]. It requires a unit one, symbol 1, the natural unit for numbers, see entry 1.10 NOTE 3 in [1]. Thus, most teachers and practicing analytical chemists conveniently ignored the SI official wordings: they had their own unit 1 and its integer multiples of 1 , including a particular value $6.022141 \times 10^{23}$ (call it the "chemical mole" for brevity and clarity) which was different from thinking in terms of a package "mole", "containing as many entities as $12 \mathrm{~g}$ of ${ }^{12} \mathrm{C}$ " [8] (call it the "physical' mole" for brevity and clarity) and its (sub)multiples of the official SI unit mole. When the concept 'amount of substance' was described as "the quantity for which the unit is the mole" $[8,13-15]$, a reasoning came into use in which a logical sequence is turned upside down: knowledge of the "mole" is needed to define ... "the quantity "amount of substance' of which the unit is the mole."

Logical reasoning requires a clear perception of what a quantity is, before we are able to define a unit for it: for example, we do not define the kilogram or the ampere before we understand 'mass' and 'electric current'.

The question must be raised about the need and justification for the introduction of 'amount of substance' in the light of remarks such as "it must be admitted that the name amount of substance is not well chosen" [15] and "It is something of a paradox that such concepts as the quantity amount of substance and its unit mole—so widely used by 
practical chemists, - are also the subjects of widespread misunderstanding" [14]. Or that "Amounts of substance are not quantities and therefore not base quantities" and "amount of substance is not a quantity in accord with the ... definition of quantity" [16].

Worthwhile is the observation that, since long, the practicing chemists (mainly in the clinical chemistry measurement community), instead of using the term "amount-of-substance concentration" (sometimes abbreviated "amount concentration") are using the term "substance concentration" or simply "concentration," thus displaying that "amount of substance" is not needed to describe the quantity "concentration." It seems to work perfectly well.

It must be repeated that "the CCU and the CCQM, requested IUPAC in 2009 to present a better name for 'amount of substance", [4]. That request was not yet answered until today- 6 years later. Is unclarity about the concept the reason? Or could the reverse be true that IUPAC is awaiting an answer to this question from CCU or CCQM?

Each of the above comments requires a careful evaluation. To this day, these must still be delivered. The confusion about 'amount of substance' should be cleared up before we can proceed to the discussion of (re)defining its associated unit. In view of the (old and present) discussions, it seems legitimate to observe that there is an ample need for ISO-TC12 as well as for IUPAC to describe the quantity 'amount of substance'. There is also an equally important role for CCQM to publish what it means by the concept "amount of substance" which the Committee carries in its name and therefore in its task [4].

Not addressing the problem might carry the risk for practicing analytical chemists to continue to ignore even more the "official" concept 'amount of substance'. It would also leave the educators in chemistry with an enduring, difficult task.

As usual, any comment, question, or amendment is welcome, preferably as a contribution to the Discussion Forum of this Journal.

\section{References}

1. BIPM, IEC, IFCC, ILAC, IUPAC, IUPAP, ISO, OIML (2008) The international vocabulary of metrology-basic and general concepts and associated terms (VIM), 3rd edn, entry 1.6. http:// www.bipm.org/vim

2. BIPM, IEC, IFCC, ILAC, IUPAC, IUPAP, ISO, OIML (2008) The international vocabulary of metrology-basic and general concepts and associated terms (VIM), 3rd edn, JCGM 200-2012 (Joint Committee for Guides on Metrology) entry 1.4. http:// www.bipm.org/vim

3. ISO 80000-1 (2009) Quantities and units, International Organization for Standardization. ISO, Geneva

4. De Bièvre P (2014) CCQM owes chemists a description of 'amount of substance'. Accred Qual Assur 19:323-325

5. De Bièvre P (2013) Second opportunity for chemists to re-think the mole. Accred Qual Assur 18:537-540

6. De Bièvre P (2014) Realizing the second opportunity to re-think the mole. Accred Qual Assur 19:411-412

7. IUPAC (2009) Report of IUPAC/ICTNS meeting in Glasgow, see minutes 8.2.4.4 http://www.iupac.org/fileadmin/user_upload/stand ing/ictns/ICTNS_09other-reports.pdf and http://www.iupac.org/body/ 027; http://www.iupac.org/fileadmin/user_upload/divisions/V/Team work/Teamwork_July_2013.pdf. see Section "revision of the SI"

8. 14th international conference on weights and measures (1971) BIPM, Paris-Sèvres http://www.bipm.org/en/si/si_brochure/ chapter2/2-1/mole.html

9. Baranski A (2012) The atomic mass unit, the Avogadro constant, and the mole: a way to understanding. J Chem Educ 89:97-102

10. Cohen ER, Cvitaš T, Frey JG, Holmström B, Kuchitso K, Marquardt R, Mills I, Pavese F, Quack M, Stohner J, Strauss H, Takami M, Thor A J (2007), International union for pure and applied chemistry, quantities and units in physical chemistry. The Royal Society of Chemistry, Cambridge (UK), Section 2.10

11. Atkins P, Jones L (1999) Chemical principles, the quest for insight. Freeman \& Co, New York, pp F43-F45

12. Furio C, Azcona R, Hondarriba-Talaia, Guisasola J, Ratcliffe M (2000) Difficulties in teaching the concept 'amount of substance' and 'mole' in the learning and teaching of the concepts 'amount of substance' and 'mole'. Int J Sci Educ 22:1285-1304

13. Rocha-Filho RC (1990) A proposition for the quantity of which the mole is the unit. J Chem Educ 67:139-140

14. Rocha-Filho RC (2011) Reproposition of numerosity as the SI base quantity whose unit is the mole. Accred Qual Assur 16:155-159

15. Mills I, Milton M (2009), Amount of substance and the mole. Chem Int 31:1-7 http://www.iupac.org/publications/ci/2009/ 3102/1_mills.html

16. Emerson WH (2014) The SI's base quantities and units. http:// www.metrologybytes.net/opEds2014.php 